\title{
La reforma almohade: del impulso religioso a la política ilustrada
}

\author{
ANDRÉS MARTÍNEZ LORCA \\ Departamento de Filosofía, UNED
}

A la memoria de José Luis Martín sabio, maestro, compañero y amigo

\begin{abstract}
RESUMEN ABSTRACT
El movimiento almohade nació como una reforma religiosa inspirada por $\mathrm{lbn}$

Tûmart y se convirtió en un imperio político y militar que dominó el Islam occidental durante más de un siglo. En este articulo se estudian la raiz teológica de dicha reforma y la estructura del poder almohade, aludiéndose también a sus grandes logros en el terreno de la

Almohad movement was born as a religious reform inspired by lbn Tûmart and developed itself into a political and military empire that dominated Western Islam for more than a century. In this paper we are aiming to study the theological root of that reform and its power structure, giving also an sketch of its great cultural achievements.
\end{abstract} cultura.

\section{PALABRAS CLAVE}

Almohades, beréberes, Ibn Tûmart, Magreb, Al-Andalus.

KEY WORDS

Almohads, Berbers, Ibn Tûmart, Maghreb, Al-Andalus.
}

Hace más de quince años, cuando redactaba un ensayo sobre la historiografía de la filosofía en al-Andalus, comencé a estudiar el movimiento almohade movido por la necesidad de comprender cómo fue posible que precisamente en ese momento histórico dominado por la hegemonía política y militar de los beréberes se desarrollara el llamado Siglo de Oro de la filosofía hispano-musul- 
mana ${ }^{1}$. Adoctrinado como estaba en el tópico de considerar a los Omeyas cordobeses como modelo de refinamiento y espíritu ilustrado en contraste con el pretendido fanatismo de los almohades, no llegaba yo a comprender tal aparente contradicción. El autor que me obligó a replantear mis viejos prejuicios, y que también me ayudó más en la tarea de desentrañar ese nudo gordiano, fue el gran filósofo cordobés Ibn Rusd, el Averroes de los latinos².

\section{RAIZ RELIGIOSA DE LA REFORMA ALMOHADE}

Inicialmente, el movimiento almohade fue un intento de reforma religiosa elaborada y defendida con tesón por un campesino beréber de las montañas del AntiAtlas, llamado Ibn Tûmart, que había tenido el valor de viajar por al-Andalus, peregrinar hasta la Meca y atravesar la mayor parte del Oriente islámico hasta llegar a Iraq con la finalidad de estudiar con los mejores maestros de su época ${ }^{3}$. A su vuelta al Magreb tuvo lugar su encuentro con Abd al-Mu'min, quien a partir de entonces se convirtió en su discípulo predilecto y que más tarde llegaría a ser el primer califa almohade. Según ha escrito uno de los mejores estudiosos del imperio almohade, "es imposible encontrar en la historia del Occidente musulmán una personalidad más destacada y una vida más extraordinaria que la de Muhammad lbn Tûmart» ${ }^{4}$. Llamado en los primeros años el Imâm de los Masmûda, sería conocido más tarde como el Mahdî ${ }^{5}$.

El núcleo teológico de la reforma almohade es su concepción radical de la unicidad divina, el tawhîd que, en palabras del propio Mahdî, "es la base de vuestra religión" y lleva a "alejar del Creador toda comparación o asociación, toda idea de imperfección, disminución, límite y dirección. (...) Quien lo sitúa en una dirección, le da una forma corporal. Quien le da una forma corporal, hace de él una criatura y quien lo convierte en criatura es como el adorador de un ídolo" ${ }^{6}$.

Aunque podemos considerar la reforma almohade en su conjunto como una novedad en el Islam medieval, sin embargo desde un punto de vista doctrinal es

"La filosofía en al-Andalus. Una aproximación histórica", en Ensayos sobre la filosofia en al-Andalus, A. MARTINEZ LoRCA, coord., Barcelona, Anthropos, 1990. pp. 7-93.

El presente articulo procede de la conferencia titulada "El racionalismo de Averroes y la reforma almohade" que imparti en el Instituto Cervantes de Casablanca el 24 de octubre de 2002, y contiene una versión parcial, ahora modificada y corregida, de aquel texto.

${ }^{3}$ Para reconstruir el origen y desarrollo del movimiento almohade, las fuentes principales son las crónicas árabes de la época, a las que aludire más adelante, los escritos de su fundador Ibn Túmart y los siguientes documentos publicados por E. LEVI-PROVENCAL : Documents inédits d histoire almohade: fragments manuscrits du "Legajo" 1919 du fonds arabe de l'Escurial, Paris, Paul Geuthner, 1928, y Trente-sept lettres officielles almohades, Rabat, Institut des Hautes Études Marocains, 1941.

${ }^{4}$ A. Huici Miranda, Historia política del Imperio almohade. Tetuán, Editora Marroqui, 1956, vol. 1, p. 23.

${ }^{5}$ De interés sobre el tema el volumen colectivo Mahdisme. Crise et changement dans l'histoire du Maroc, A. KadDOURI, coord., Casablanca, 1994

' Carta a la comunidad almohade, en É. Lévi-ProvençAL, Documents inédits d' histoire almohade, cit., pp. $7-8$ 
posible distinguir en ella con claridad estas diversas influencias: el zahirismo, aprendido con toda probabilidad en Córdoba por Ibn Tûmart de algún discípulo de Ibn Hazm, del que tomó la defensa del estudio de las fuentes y el consiguiente alejamiento del principio de autoridad, así como el rechazo de la analogía como criterio jurídico; la escuela asarí de la que aprovechó buena parte de sus teorías teológicas y en especial su pretensión de racionalizar la fe y su abandono de todo antropomorfismo religioso; los mutazilies, de quienes continuó a su modo el racionalismo y la defensa a ultranza de la simplicidad y unicidad de Dios, con la consiguiente negación de los atributos divinos; y el siismo, del que adoptó su doctrina del imamato y su creencia en el Mahdî. Puede reconocerse también la influencia de Algacel, aunque es objeto de polémica la importancia que alcanzó en la configuración del pensamiento de $\mathrm{Ibn}$ Tûmart ${ }^{7}$. Para algunos se trataría más bien de una coincidencia de fondo en la crítica al tradicionalismo jurídico y respecto al papel del misticismo en una deseada reforma religiosa.

\section{LA AQÎDA DE IBN TÛMART}

Los escritos dispersos de Ibn Tûmart fueron recopilados posteriormente por el califa Abd al-Mu'min. A comienzo del siglo xx fue editado este valioso manuscrito (del que seguimos careciendo todavía de traducción castellana), precedido de una interesante introducción redactada por el arabista húngaro I. Goldziher ${ }^{8}$. Sobresale por su importancia entre esos escritos la 'Aqîda o Profesión de $\mathrm{Fe}^{9}$. En un lenguaje teológico de alto nivel especulativo, se intenta demostrar en esas páginas la existencia de Dios con argumentos a posteriori similares a los usados por la Escolástica cristiana y se defiende de modo radical la unicidad divina. Llama la atención el dominio de la lógica y del razonamiento silogístico de que hace gala su autor. Veamos algunos puntos concretos de este escrito fundamental dentro de la reforma almohade.

Comienza la Profesión de Fe recordando los cinco pilares del Islam: la creencia en la unidad divina, la oración, la limosma legal, el ayuno en el Ramadán y la peregrinación. Más adelante, se afirma la existencia del Creador como una necesidad de la razón ${ }^{10}$. Es gracias al Creador como el hombre pasa de la no-existencia a la existencia. Ibn Tumart acude ahora a una hermosa descripción del origen

7 Véase M. FLETCHER, «lbn Tûmart's teachers: the relationship with al-Ghazâli», en Al-Qantara, Madrid, 1997, vol. XVIII, 2, pp. 305-330. Fletcher parece forzar los argumentos y caer en algunas contradicciones como, por ejemplo, considerar paralelos a Algacel y a los "intelectuales almohades" Averroes e Ibn Tufayl. En contra del aparente objetivo de la autora, lo que se deduce de su artículo es más bien la existencia de un proyecto político conjunto, por parte del propıo Algacel y del mistico andalusí lbn Arabi, para apoyar al emir almorávide Yûsuf.

* Le Livre de Mohamed ibn Toumert, Mahdi des Almohades, edición del texto arabe por D. Luciani e Introdución de I. Goldziher, Argel, Imprimerie Orientale Pierre Fontana, 1903.

9 Hay traducción írancesa de H. Massé en Mémorial Henri Basset. Nouvelles études nord-africanes et orientaies, París, 1928, vol. II, pp. 105-117.

10 Aqîda, traducción citada, pp. 105-106 
del hombre tomada del Corán y que representa un paso adelante respecto del relato biblico: «hemos creado al hombre de la quintaesencia de la arcilla; después, hemos hecho de ella una gota de esperma en un receptáculo sólido; después, hemos hecho de la gota un grumo de sangre; luego, hicimos del grumo de sangre un trozo de carne; luego, cambiamos este trozo de carne en hueso; vestimos de carne los huesos; y después, lo hemos producido como otra creación. Bendito sea Allâh, el mejor de los creadores $j$ " ${ }^{11}$

Encontramos también en la 'Aqîda una reformulación del conocido argumento del primer motor inmóvil ${ }^{12}$. Los cielos, la tierra y todas las criaturas existen gracias a la existencia del Creador, pues la contingencia del primer movimiento exige un agente que lo haga posible. "Todo aquello de lo que se reconoce que existe después de no haber existido, es forzosamente creado».

La demostración de la existencia divina por la prueba de la contingencia es asimismo utilizada por Ibn Tûmart, quien distingue tres categorías de criaturas: los seres vivos dotados de razón, los seres vivos privados de razón y los seres inanimados privados de percepción. Los primeros son impotentes para crear, los segundos más todavia y los seres inanimados se encuentran en una escala más baja aun. "Se reconoce, pues, que Allâh es el creador de todas las cosas según su palabra divina: Allâh es el creador de todas las cosas, él cuida de todo, Corán, $X X X \mid X, 63 » 13$.

A continuación, se pretende subrayar la unicidad divina rechazando cualquier analogía entre la criatura y el Creador. «El Creador no tiene comienzo; ahora bien, quien tiene necesariamente un comienzo, tiene algo antes de él, quien tiene algo antes de él tiene algo después de él, quien tiene algo después de él tiene un límite, quien tiene un límite es creado y quien es creado tiene necesidad de un creador. $Y$ el Creador es el alfa y el omega, lo evidente y lo oculto, todo lo sabe, es el primero sin comienzo y el último sin fin, lo evidente sin delimitación y lo oculto sin particularización, el que existe de una manera absoluta, sin comparación ni modalidad" ${ }^{14}$. Encontramos aquí no sólo un seco rechazo del antropomorfismo, sino algo también más problemático, el reconocimiento explícito de la imposibilidad para el hombre de penetrar mediante la razón la esencia divina. Aparece, pues, en este sugestivo texto almohade la noción de límite para el conocimiento humano: " Hay un límite para la razón humana en el cual ella se detiene sin sobrepasarlo» ${ }^{15}$.

Del terreno dogmático hay un salto después al terreno de la hermenéutica del texto sagrado. Ibn Tûmart admite que existen textos en el Corán «que se prestan a equivocos". Critica a quienes «siguen lo que es equívoco en el Corán, y esto por

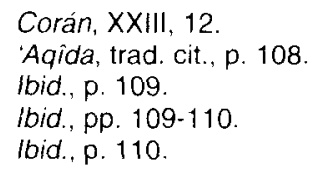


un deseo de desorden y por un deseo de interpretar [a su antojo] ${ }^{16}$. Pero no ofrece una alternativa hermenéutica concreta al creyente perplejo, salvo la ya citada de no dejarse llevar por un afán interpretativo y el consejo de no restringir a Dios dentro de las categorias mundanas de "antes y después, arriba y abajo, derecha e izquierda, delante y detrás, todo y parte» ${ }^{17}$. Sabemos, no obstante, por otros textos que los almohades defendieron en tales ocasiones conflictivas una interpretación alegórica del texto sagrado, es decir, el ta'wîl.

Aunque con los límites que ya hemos advertido, debemos reconocer «que la imperfección es imposible en el Creador» y que él es «necesariamente viviente, sabio, poderoso, dotado de voluntad, de oído, de vista, de palabra, y todo esto sin que se conciba modalidad " 18 . De igual modo hay que considerar como imposible cualquier cambio en la divinidad ${ }^{19}$. Observamos aqui una oscilación entre una teología negativa (decir lo que no es Dios) y una teología positiva (afirmar las perfecciones de Dios). Dado que los almohades, para evitar toda visión antropomórfica de la divinidad, no admitieron la existencia de atributos en Dios, me parece más coherente con su posición doctrinal la formulación de una teologia negativa que la de una positiva, aunque ello plantee sus dificultades al creyente a la hora de pretender hablar de Allâh y de sus perfecciones.

Tambien encontramos en la Profesión de Fe almohade una afirmación rotunda de la predestinación y de la presciencia divinas. Echando mano del atomismo griego que se difundió en el pensamiento islámico, sobre todo entre los mutakallimûn, como rara avis dentro del mundo medieval, Ibn Tumârt afirma de manera tajante: «nada escapa a su sentencia inmutable: ni un átomo...se mueve en las tinieblas de la tierra sin que él lo haya predestinado y sabido de antemano" ${ }^{20}$.

Partiendo de las palabras del Corán «Dios tiene los nombres más bellos", se abordan en la 'Aqîda los nombres de Allah. El Islam es, dentro de las tres grandes religiones monoteístas, la que más importancia le ha concedido a este tema, hasta el punto de insertarlo en la práctica piadosa. Según un hadiz, «Dios tiene noventa y nueve nombres - cien menos uno-; quien los sepa de memoria, entrará en el paraíso". Encontramos un desarrollo espléndido de esta tradición islámica en la obra titulada Futuhat del gran maestro sufí Ibn Arabí de Murcia. Sin embargo, en el judaismo no se ha valorado esto, salvo en la tradición cabalística. En el cristianismo existe una tradición teológica sobre el tema que parte de la obra Los nombres de Dios, atribuída al Pseudo-Dionisio. Pero, a diferencia de lo que sucede con los nombres de la Virgen cuyas letanias forman parte de la religiosidad popular, su tratamiento se ha centrado de modo fundamental en el ámbito especulativo y literario. Un curioso ejemplo de influencia sufí, pero con un tratamiento más autónomo

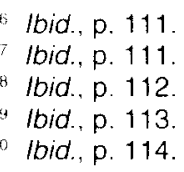


de lo que a veces se ha creído, es el que ofrece el pensador mallorquín Ramón Llull en su obra El cent noms de Deu, escrita el año 1289 en Roma ${ }^{21}$.

Ibn Tûmart repite y acepta aquellos nombres que el Corán le atribuye a Dios, pero al mismo tiempo considera como ilícitas por parte del hombre las innovaciones en este terreno, o lo que él llama la analogía, la etimología y la convención a propósito de los nombres divinos. No compete al hombre, por tanto, poner nombres a Dios porque ello, según él, sería contradictorio con su propia naturaleza. «El hombre se llama Zayd y 'Amr; nace sin tener nombre y se ponen de acuerdo a propósito del nombre que llevará; pero no pertenece al hombre ejercer poder sobre su creador y, como consecuencia, darle un nombre que él no se ha dado a sí mismo en su Libro: lo que Dios ha descartado de su persona en su Libro, él lo ha descartado del hombre» 22 .

\section{ALGUNAS INTERPRETACIONES DE LA REFORMA RELIGIOSA ALMOHADE}

El primero que en España prestó atención al libro de Ibn Tûmart, y con él al Estado almohade, fue el maestro de arabistas Miguel Asín en un temprano artículo que todavía merece la pena releer ${ }^{23}$. Siguiendo a Goldziher, Asín rebaja la influencia de Algacel sobre el Mahdî aunque admite que «en el pensamiento y en la conducta de Ibn Tûmart se revelan algunos síntomas de influencia indirecta ejercida por el ambiente teológico de su época, que tanto debía al gran renovador del islam oriental” ${ }^{24}$. Dentro del Derecho, le reconoce a los almohades el mérito de haber impuesto de manera progresiva el estudio de las fuentes y de haber acabado "con los casuísticos manuales de la escuela mâlikî». Las bases del Derecho islámico se reducen para los almohades a tres: el Corán, la tradición profética debidamente contrastada y el consenso unánime de la comunidad islámica, es decir, la iymâ'. Para Asín es la escuela zahiri la que más caracterizaría la concepción almohade del figh.

Podemos observar una actitud racionalista en el desapego de lbn Tumârt respecto del tradicionalismo jurídico islámico. En efecto, comenzó criticando a los ulemas almorávides, y más allá de ellos a los juristas asaries, por haber fundamentado el Derecho islámico sobre la base de la mera suposición. Para él, sin embargo, sólo el saber podía admitirse como criterio de verdad. "Lo más valioso que ha sido ambicionado, lo más hermoso que ha sido realizado, es el saber. Dios

21 Véase «Paralelismo e influencia entre el Islam y el Cristianismo:El cent noms de Deu de Ramon Llull, de Felipe MAillo SALGADO, en Bulletin of the Faculty of Arts. Número especial: III Congreso de Cultura Andalusi, Cairo University Press, 1992, pp. 189-215.

2.2 Agìda, cit., p. 115.

23 "Origen y carácter de la revolución almohade", en Revista de Aragón, 1904, vol. V, pp. 498-506, reproducido en Obras Escogidas II y III. De Historia y Filologia Árabe, Madrid, CSIC-Escuelas de Estudios Árabes de Madrid y Granada, 1948, pp. 1-12; cito por esta reedición.

24 Art. cit., p. 5. 
lo ha puesto como fundamento de la conducta recta. (...) Eso significa que Dios no ha creado en los mundos superior, medic e inferior, nada, aparte del saber, con lo que se pueda distinguir entre negación y afirmación, entre lo verdadero y lo falSO" 25 .

En el plano teológico Asín considera a lbn Tûmart un revolucionario dentro del Occidente musulmán, pues en su afán por eliminar el formalismo huero de los alfaquies y el antropomorfismo religioso tan enraizado en el Magreb, aquél se dejó influir notablemente por el racionalismo de los asaries y el librepensamiento de los mutazilies. No le pasó desapercibida al ilustre arabista la reforma moral que trajo consigo el movimiento almohade y que convirtió a su fundador en un severo crítico, en público y en privado, de las costumbres que estimaba degradadas y corrompidas respecto al mensaje islámico originario.»Expulsado de las capitales del imperio, su celo hubo de ejercitarse en el seno de su tribu y arrogándose muy pronto el título de Mahdî, equivalente al de Mesías, el movimiento por él iniciado tomó los caracteres de una revolución política contra la dinastia imperante" ${ }^{26}$. La reforma almohade buscó asimismo una mayor austeridad de la vida pública, algo fácil de asimilar entre sus primeros adeptos, los campesinos pobres de las montañas del Atlas.

Goldziher no traspasó el punto de vista especulativo en su estudio de lbn Tumârt, dejando fuera de su análisis las causas sociales que pudieran explicar el triunfo de la revolución política almohade. Asín, por su parte, reconoció esa laguna, que él estimaba razonable dadas las dificultades metodológicas que un enfoque de otro género llevaba consigo y las investigaciones históricas concretas que exigia.

En los últimos años algunos estudiosos han prestado atención a la plasmación de los lemas religiosos almohades en diferentes soportes como la cerámica ${ }^{27}$, las monedas ${ }^{28}$ y la epigrafía ${ }^{29}$ bajo el prisma común de la "propaganda política". E profesor Acién ha analizado de modo especial los aspectos teóricos relativos al tema. La profesora Martínez Núñez ha comparado a los omeyas andalusies con los almohades, subrayando la utilización generalizada de elementos religiosos por parte de estos últimos: "una de las caracteristicas de la epigrafía almohade (...) es la presencia masiva de citas del Corán en todo tipo de inscripciones, tanto en

${ }^{25}$ Le Livre de Mohamed ibn Toumert, cit., II, 2. Sobre este punto puede consultarse con provecho T. Nagel, "La destrucción de la ciencia de la saria por Muhammad b. Tûmart" en Al-Qantara, vol. XVIII, 2, cit. pp. 295-304.

26 Art. cit., p. 11

27 M. ACIEN Al.MANSA, "Cerámica y propaganda en época almohade", en Arqueologia Medieval, 1996, 4, pp. 83-191.

${ }^{28} \mathrm{M}$. Vega Martin, S. Pena Martin y M. C. Feria Garcia el mensaje de las monedas almohades. Numismática, traducción y pensamiento islámico, Cuenca, Ediciones de la Universidad de CastillaLa Mancha, 2002; S. Fonterila Ballesta, "Numismática y propaganda almohade", en A/-Qantara, vol. XVIII, 2, cit., pp. 447-462.

29 M. A. MARTinez NúnEz, “Epigrafia y propaganda almohades”, en Al-Qantara, vol. cit., pp. 415-445, y «El Califato Almohade. Pensamiento religioso y legitimación del poder a través de los textos epigráfiCos", en Ultra mare: Mélanges de langue arabe et d'islamologie offerts à Aubert Martin, F. Bauden, ed., Lovaina-Paris-Dudley, Peeters, 2004. 
epígrafes de mezquitas como en aquellos que discurren por las puertas monumentales de Rabat y Marrakech, en dependencias de recintos fortificados y de viviendas. Lo primero que llama la atención (...) es el contraste existente entre lo que sucede en el período almohade, y a partir de él, y lo que se observa, por ejemplo, en los textos epigráficos de la etapa omeya de al-Andalus, durante el emirato y el califato, que se caracterizan por la ausencia de citas coránicas, que se reservaban a las inscripciones de las mezquitas y a los epitafios" ${ }^{30}$.

Por su parte, los autores de El mensaje de las monedas almohades han llevado a cabo una compleja tarea, mezcla de acribia filológica y hermenéutica de textos. En su estudio de la ideologia almohade a partir de las monedas, podemos leer esta rotunda conclusión: "Hemos insistido repetidamente en que las dos leyendas numismáticas almohades fundamentales son : La disposición toda es de Dios y El Mesias [al-Mahdi] es el Guia de la Comunidad, el Ejecutor de la Disposición de Dios, que expresan la legitimidad del Estado sobre una base mesiánica y teocrática. Teocrática en el sentido de que existe un vínculo indisoluble entre lo secular y lo religioso, en lo político, y una falta de distinción entre lo individual y lo comunitario, en lo moral» ${ }^{31}$.

Sobre tales supuestos, no son de extrañar las severas críticas a que ha sido sometido el poder almohade en su conjunto. Así, M. Fierro ha considerado como distintivo del almohadismo la separación entre la élite y la masa. Los autores de El mensaje de las monedas almohades, desde una perspectiva similar, hablan claramente de 'dos religiosidades'. "Dado todo lo anterior, no es descabellado afirmar que el dirham almohade expresa, en sus dos caras, uno de los mensajes más característicos de la construcción ideológica almohade, y uno más de los aspectos de su sincretismo: el de la coexistencia de una religiosidad para las elites y otra para el vulgo..." ${ }^{32}$. Y M.A. Martínez Núñez concluye calificando "de una manipulación por parte de la jerarquía mu miní a "ese nuevo papel predominante de la religión" ${ }^{33}$.

No puedo entrar ahora a fondo en las sugestivas y polémicas cuestiones que suscitan los estudios antes citados. Sin duda, constituye un paso adelante en nuestro conocimiento del mundo almohade el que éste sea analizado con una metodología más adecuada y en algunos aspectos hasta ahora desatendidos (la ideología religiosa, el arte, la economía, la etnología, etc.). Pero ciertas conclusiones me parecen muy discutibles y yo, desde luego, no las puedo compartir: por ejemplo, el considerar como algo específico del almohadismo las llamadas «dos religiosidades".

Que en las grandes religiones históricas podamos distinguir la religiosidad de los teólogos/sacerdotes y la religiosidad de las masas, es decir, la fe de los inte-

\footnotetext{
30 "El Califato almohade...", cit., p. 196

El mensaje de las monedas almohades, cit., pp. 250-251.

Ibid., p. 246.

33 "El Califato Almohade...", cit., p. 209.
} 
lectuales y la fe del carbonero, me parece que no necesita demostración. A pesar del intento siempre latente, y a veces patente, de la clase sacerdotal/teológica por dominar y beneficiarse de la religión establecida, es indudable que dicha clase ha procurado, en todas las épocas y en todos los credos, que la separación respecto de las masas populares no se petrificara hasta el punto de llegar a una ruptura, pues, en definitiva, la fuerza de los teólogos/sacerdotes reside en la adhesión que sean capaces de producir en el pueblo llano.

Pero la crítica de Averroes a los teólogos islámicos, es decir, a los mutakallimûn, en el Fasl al-Maqâl, la consideración de la filosofía por parte del sabio cordobés no como sierva o ancilla de la teologia sino como "amiga y hasta hermana de leche de la religión", y su propuesta de que la masa camine "por una senda media en la cual se vea exenta de la humillación propia de los que creen sin razones de ninguna especie", van en la dirección contraria a lo que afirman los críticos del almohadismo. Creo que tenía razón Montgomery Watt cuando escribió : "El mérito de Ibn Rusd consiste aqui en haber entendido que existía una continuidad esencial entre su propia religión filosófica y la de las masas»" 34.

Si a esto añadimos la protección a los médicos-filósofos por parte del poder almohade, la utilización preferente durante esa época de una letra cursiva, el nasji, en detrimento del cúfico, la redacción en lengua beréber de algunos escritos de lbn Tumârt y la traducción del Corán a esa lengua autóctona magrebí ${ }^{35}$, llegaremos más bien a unas conclusiones opuestas a las que venimos comentando. Asín comparó con acierto la reforma almohade con la reforma protestante y no dejó de advertir la raiz popular de ambas.

\section{LOS ALMOHADES EN LAS FUENTES HISTÓRICAS ÁRABES}

Para completar de algún modo el análisis de la 'Aqîda que antes he realizado y la síntesis jurídico-teológica que nos ofrecian Goldziher y Asín, me parece conveniente acudir ahora a las fuentes históricas árabes para tener una perspectiva más amplia de lo que en realidad significó en el mundo medieval la reforma almohade ${ }^{36}$.

Una fuente importante es la obra Kitâb al-'llbar del gran historiador árabe del siglo XIV, de origen andalusí, Ibn Jaldún. Antes de hablar en detalle de Ibn Tumârt y

34 W. Montgomery Watt, “Philosophy and Theology under the Almohads", en Actas del Primer Congreso de Estudios Arabes e Islámicos, Madrid, 1964, p. 107.

35 Véase El mensaje de las monedas almohades, cit., p. 261, donde se alude a la evolución del sistema caligráfico árabe y a la atención prestada por los almohades a la lengua beréber.

36. Entre los estudios publicados en los últimos años sotre los almohades, destacaremos estos dos: El retroceso territorial de al-Andalus: Almorávides y almohades, siglos $x /$ al $x m, \mathrm{M} .{ }^{a} \mathrm{~J}$. VIGuERA, Coord., Madrid, Espasa-Calpe, 1997 (forma parte de la monumental Historia de España dirigida por Ramón Menéndez Pidal; de interés especial sobre el tema los capítulos dedicados a la Religión y a la Filosofía redactados, por M. Fierro y E. Tornero, respectivamente); D. Urvoy, Penseurs d'al. Andalus. La vie intellectuelle à Cordoue et Séville au temps des empires berbères (fin xi siècle-début xIII siécle), Toulouse, 1990 
de la fundación del Estado almohade, traza en ella una pincelada de ambos al describir el fin de los almorávides. El fundador del movimiento almohade aparece en esta primera aproximación como «un jurista versado en la ciencia, que daba consejos y practicaba la enseñanza». Desde el punto de vista militar, Ibn Jaldún destaca estos tres hechos: la derrota de Tâsufîn ibn 'Alí en Tremecén ( año 1144) ante el ejército almohade comandado por 'Abd al-Mûmin, que se apoderó así del Magreb central; el asedio y posterior toma de Marrakech, con la que concluia el poder almorávide en el conjunto del Magreb (año 1147); y la ocupación de al-Andalus por los almohades (año 1156). “Unidos tras la misma palabra, los Masmûda efectuaron varios ataques contra Marrakech. El viento de los Lamtûna se apagó en al-Andalus, las fuerzas almohades triunfaron y su mensaje se extendió entre los beréberes del Magreb» ${ }^{37}$. Durante más de un siglo los almohades dominaron el Islam occidental: el año 1269 se eclipsaría su poder con la conquista de Marrakech por los merinies.

Al centrarse más adelante en la biografía de lbn Tûmart, Ibn Jaldún pone de relieve estas dos cualidades que le adornaban: el amor a la ciencia y la piedad religiosa. Dentro de su formación netamente oriental, destaca su etapa de aprendizaje en Irak, «donde se relacionó con los más grandes sabios y los teóricos más eminentes, sacando gran provecho de ello", y la influencia sobre el joven beréber de los teólogos asaríes, quienes le habrían abierto la mente en la interpretación racional de los textos equívocos del Corán. Desde el punto de vista externo nos ofrece este sobrio retrato del fundador almohade: "Llevaba un vestido de lana remendada, se dedicaba con frecuencia a ejercicios ascéticos y a prácticas piadosas" ${ }^{38}$.

No le pasó desapercibida tampoco al gran historiador magrebí la estructura que podriamos llamar "concéntrica" del poder almohade. El Mahdî entresacó a los más sobresalientes entre los Masmûda para formar el Consejo de los Diez o al-Yamâ'a; el llamado Grupo de los Cincuenta designaba a un círculo próximo al poder, pero diferenciado del núcleo consultivo principal. A sus compañeros les llamó at-Talaba ("los estudiantes") y a la masa de sus seguidores al-Muwahhidin ("los unitarios o almohades"). En un historiador magrebí que vivió al final del imperio almohade, Ibn al-Qattân, encontramos expuesta con más detalle esa compleja estructura de poder en torno al califa: primer rango, los Diez; segundo, los Cincuenta; tercero, la asamblea de los Setenta; cuarto, los talaba; quinto, los hâfiz, hijos de los talaba que eran especialmente instruidos; y asi, hasta un total de trece categorias ${ }^{39}$.

Le debemos a Emile Fricaud una espléndida reconstrucción histórica de este círculo de poder almohade que fueron los talaba, hasta ahora poco estudiado ${ }^{40}$.

${ }^{37}$ IBN KHALDÚn, Peuples et nations du monde, selección y traducción del Kitâb al-'lbar por A. Cheddadi, Paris, Sindbad, 1986, vol. 2, p. 521; cito en adelante por esta edición.

38 lbid., p. 545.

39 Nazm, edición de Mahmûd 'Alî Makkî, Tetuán, 1964, Beirut 1990, 2. a ed. p. 82.

"40. Fricaud, "Les talaba dans la société almohade (le temps d' Averroes)", en Al-Qantara, vol. XVIII, 2, cit., pp. 331.387 
Los primeros talaba (plural de tâlib) fueron los compañeros de lbn Tûmart que lo acompañaron en su viaje de regreso al Magreb desde Bagdad, y que formaron parte después del Consejo de los Diez y de los Cincuenta. A partir del primer califa almohade, los talaba se constituyeron en una corporación de "intelectuales" del régimen, extendiendo su presencia a lo largo y ancho del nuevo imperio. Sus descendientes fueron educados por decisión de 'Abd al-Mu'min en una madrasa creada ex professo para ellos en Marrakech, llegándose a contar hasta tres mil alumnos. No formaban parte del gobierno pero desempeñaron un papel fundamental en el plano ideológico-político, como se trasluce de las crónicas no censuradas en el periodo meriní y como indica también su lugar preferente en el protocolo de corte.. Encargados corporativamente de elaborar la reflexión oficial en toda circunstancia, especialistas de la propaganda almohade, difusores de las directivas califales, miembros de los tribunales de justicia que tenian que pronunciarse sobre la malversación de un alto funcionario o las desviaciones doctrinales de un sabio, participaban también en múltiples tareas de intendencia" ${ }^{41}$.

Por otra parte, hay dos aspectos centrales que explicarian, según Ibn Jaldún, la consistencia del poder almohade y que, en mi opinión, son quizá los factores decisivos a la hora de analizar este fenómeno histórico: $1 .{ }^{\circ}$, la base tribal del poder almohade, fiel reflejo antropológico del mundo beréber, y que le proporcionó a aquél una increible fuerza de cohesión social o 'asabiyya; y $2 .^{\circ}$, la union entre una religión arraigada en el pueblo y una sólida 'asabiyya tribal que lleva necesariamente a la victoria en la lucha por el poder político. O como dirá con carácter genérico en la Muqaddima, pero poniendo como ejemplo precisamente a los almohades: «una dinastía que inicia su carrera apoyándose en la religión, duplica la fuerza de la 'asabiyya que coopera a su institución » ${ }^{42}$.

Para concluir esta aproximación a la reforma almohade, utilizaré otra fuente histórica árabe más próxima a los hechos:el Kitâb al-mu' yib fî talijs ajbâr alMagrib o Libro de lo admirable en el resumen de las noticias del Magrib ${ }^{43}$ de Abû Muhammad 'Abd al-Wâhid al-Marrâkusî, que nació en Marakech el año 1185, viajó por al-Andalus almohade y se exilió al Oriente islámico, donde murió hacia el año 1224.

En los párrafos que le dedica a lbn Tûmart ${ }^{44}$ destaca de éste su fina inteligencia, su profundo ascetismo y su callada ambición política. En cuanto a las influencias sobre su pensamiento teológico-jurídico, 'Abd al-Wâhid señala sólo la de los asaries, mutazilies y siies, olvidándose de los zahiries.

Como regla general, los gobernantes almohades aparecen como hombres cultos, protectores de los sabios y amantes de los libros. Valga como ejemplo de

4 Ibid., p. 385

${ }^{42}$ Muqaddima, libro III, capitulo 5.

${ }^{43}$ Hay traducción castellana del Mu' yib por A. Huici Miranda en Colección de Crónicas Arabes de la Reconquista, volumen IV, Tetuán, Editora Marroqui, 1955, que cito en adelante.

${ }^{44}$ Ibid, pp. 136-153. 
ello su logro de convertir a la capital del imperio almohade, Marrakech, en un centro de ilustración: "Se había establecido su costumbre de escribir al pais y de hacer ir a su capital a los sabios de todas las materias y especialmente a los de la ciencia especulativa y los llamados tâlibes [es decir, los talaba] de la capital, que eran unas veces muchos y otras pocos " ${ }^{45}$. Recordemos por nuestra parte que los tres principales sabios andalusies de la época, Ibn Tufayl, Averroes y Avenzoar el nieto estuvieron estrechamente ligados a la corte almohade y a su capital, en la que vivieron y donde todos ellos murieron.

También se distinguieron los califas almohades por un afecto especial hacia alAndalus, tierra que protegieron militarmente de los reinos cristianos, a la que viajaron con frecuencia y en cuyo suelo dejaron una magnifica huella urbanística y arquitectónica. Hay una escena de singular dramatismo y en extremo reveladora de ese afecto, que se nos ha conservado en un texto histórico poco difundido en España, escrito por el historiador marroquí Ibn 'Idârî al comienzo del período meriní. En ella el califa almohade al-Mansûr, en el lecho de muerte, da a sus allegados las últimas recomendaciones. "Luego dijo, después de bajar la cabeza un rato y de derramar lágrimas: 'Os recomiendo el temor de Dios y los huérfanos y la huérfana'. El jeque Abû Muhammad 'Abd al-Wâhid le preguntó: ' $O$ Oh, señor nuestro, oh, Amîr al-Mu'minîn, ¿quiénes son los huérfanos y la huérfana?' Dijo: 'La huérfana es la península del Andalus y los huérfanos sus habitantes, los musulmanes. Guardaos de descuidar lo que le conviene de elevar sus muros, y de defender sus fronteras, de organizar sus soldados y de hacer numerosos a sus súbditos. Sabed, hónreos Dios, que no hay en nuestra alma una preocupación mayor que la suya y nosotros la confiamos ahora a Dios y a vuestro buen cuidado; mirad por los musulmanes y haced que las leyes sigan sus buenos caminos» " 46 .

De al-Andalus los almohades prefirieron Sevilla. En ella levantaron los bellos monumentos que todavía llenan de admiración a quien los contempla: la Giralda, la Torre del Oro y el Alcázar. Este decidido impulso al desarrollo urbano mereció el reconocimiento de un notable historiador, contemporáneo de Averroes, secretario en Sevilla y ligado estrechamente al círculo de poder almohade. "Él [Abû Ya' qûb Yûsuf] fue quien eligió Sevilla como capital, y ordenó construir sus murallas, por el lado del río, a sus expensas...; dio paso sobre su río, con un puente, gran obra arquitectónica, asentado en firmes bases, para que pudieran cruzarlo los habitantes de la ciudad y los del Aljarafe... Trajo el agua por conducción para que bebieran los habitantes de la ciudad y de su alcázar. Construyó allí también la aljama grande y noble, para que la gente estuviera holgada... igualándola a la de Córdoba en amplitud... Construyó también la alcazaba hasta la mitad, cimentándola incluso en el agua... " ${ }^{47}$.

45 Ibid., p. 281

${ }^{46}$ Ibn 'Idârî al-Marrâkusî, Al-Bayân al-Mugrib, traducción de A. Huicı MiRanda en Colección de Crónicas Arabes de la Reconquista, vol. II, Tetuán, Editora Marroqui, 1953, tomo I, p. 210.

47 Ibn Sâhib al-Salâ, Al-Mann bi-l-imâma, traducción de A. Hulci MiRanda, Valencia, Anúbar, 1969, pp. 234-235. 
Del primer califa almohade, 'Abd al-Mu'min, el historiador 'Abd al-Wâhid pone de relieve sus excepcionales dotes como estratega militar y como verdadero artífice del nuevo Estado, que abarcaba ya todo el Magreb y al-Andalus. "Se posesionó 'Abd al-Mu'min de toda Ifrîqiya, incluyéndola en el reino del Magrib y reinó en su vida, desde Trípoli del Magrib hasta el Sûs extremo, en el país de los masmûda y la mayor parte de la península del Andalus, reino como no sé que hubiese reunido nadie antes que él, desde que se instaló la dinastía de los Banû Umayya, hasta su tiempo" ${ }^{48}$. En efecto, el imperio almohade representó el momento de mayor peso político del Magreb a lo largo de su historia. Nunca como entonces brilló tan alto el nacionalismo beréber que llegó a dominar en el plano político, ideológico y militar todo el Islam occidental. Esa fuerte personalidad política y militar de 'Abd alMu'min no ahogó en él su gusto literario: «Era aficionado a la literatura, distinguía a sus cultivadores, se emocionaba con la poesia y la premiaba" ${ }^{49}$.

El califa almohade más ilustrado y que podía competir con el califa omeya cordobés al-Hakâm II en su protección de la cultura, fue el hijo de 'Abd al-Mu'min y primer gobernador almohade de Sevilla, Abú Ya'qûb Yûsuf, al que antes nos hemos referido como mecenas artístico e impulsor de la capital andaluza, y que murió en el sitio de Santarem defendiendo la frontera occidental andalusí. Según la misma fuente que venimos utilizando, estudió lengua árabe, gramática y el Corán con maestros andalusies en Sevilla y se aficionó a la filosofía de la que reunió una gran biblioteca. Protegió, entre otros, a Ibn Tufayl y a Averroes. "No cesó [Yûsuf] de reunir libros de las regiones del Andalus y del Magrib y de buscar sabios, en especial los de la ciencia especulativa, hasta que se le reunieron más que se le habian reunido a ninguno de los reyes del Magrib antes de él» 50

En su hijo al-Mansûr encontramos ya, sin embargo, síntomas de decadencia cultural, una creciente desconfianza hacia la filosofía y un intento claro por consolidar su poder político mediante el apoyo en los sectores religiosos conservadores. Además de tener el baldón de haber condenado a Averroes, aunque es cierto que presionado por los alfaquíes cordobeses que aprovecharon así la resaca de la victoria militar de Alarcos para ajustar cuentas con el pensamiento racionalista de su ilustre paisano, volvió también este califa a la siniestra práctica de la quema de libros de ciencia considerados peligrosos para la ortodoxia. Se esforzó en anular el malikismo, logrando debilitar su influencia social pero no suprimirlo. Tiene, por otra parte, el mérito de haber sido el verdadero creador de la ciudad de Rabat cuyos grandes monumentos, como la mezquita aljama y las murallas, inició su padre.

Los califas almohades posteriores tienen un perfil plano desde una perspectiva intelectual. No hay ya casi huellas del impulso re!igioso de Ibn Tûmart, ni de la visión política de 'Abd al-Mu'min, ni de la pasión for la ciencia de Yûsuf. La política almohade va perdiendo inexorablemente su vigor inicial, su espíritu expansivo,

\footnotetext{
Kitâb al-Mu'yib, trad. cit., p. 183

lbid, p. 178.

Ibid., p. 194.
} 
y se va haciendo cada vez más instrumental y endogámica: sólo se busca el mantenimiento en el poder.

Señalemos, por último, el contraste entre los almorávides y los almohades en el terreno cultural. Desde este punto de vista la diferencia entre ellos es como de la noche al dia. Al-Saqundî, por ejemplo, en su conocida obra se burla a fondo de la ignorancia supina de Yûsuf ibn Tâsfîn, el príncipe almorávide conquistador de alAndalus ${ }^{51}$. Por el contrario, de acuerdo con el testimonio de Averroes transmitido por el historiador 'Abd al-Wâhid al-Marrâkusî resulta muy difícil encontrar en la historia de cualquier pueblo ilustrado gobernante alguno que pueda competir en filosofía con el califa almohade Abû Ya'qûb Yûsuf: “...y volviéndose [el califa] hacia Ibn Tufayl, se puso a hablar de la cuestión que me había preguntado [la eternidad del mundo] y a citar lo que dijeron Aristóteles, Platón y todos los filósofos, aportando al caso, además de ellos, los argumentos de la gente del Islam y vi en él una abundancia de conocimientos, que no creo se encuentre en ninguno de los que se ocupan de este asunto, dedicados a él» 52 .

Yûsuf ibn Tâsfîn persiguió la difusión del pensamiento filosófico y protegió al malikismo, como lo atestigua la misma fuente. Muy distinta fue la actitud de los herederos político-religiosos de Ibn Tûmart: «hay que prescindir en absoluto de la tesis de Renan sobre el fanatismo almohade y su persecución de los filósofos; 'Abd al-Mu'min condenó abiertamente los 'autos de fe' realizados con los libros de Algacel y de otros pensadores por los almorávides; y sus reformas de la enseñanza y sus obras artisticas no nos dejan sospechar tan cerrado fanatismo. Cuando el año 1163 subió al trono Yûsuf, este ambiente de libertad intelectual llegó a su apogeo, naturalmente al modo como se entendía en el Islam y en pleno siglo $x \mid 1 »{ }^{53}$.

La influencia de los almohades en el pensamiento andalusi, y de modo especial en Averroes, fue advertida hace tiempo por I. Goldziher y L. Gauthier. En los últimos años ha sido subrayada por R. Brunschvig, W. Montgomery Watt y D. Urvoy ${ }^{54}$. Tampoco ha dejado de llamar la atención de los intelectuales árabes contemporáneos. Entre ellos destaca por su brillantez teórica el marroquí Mohamed Ábed Yabri, quien, dentro de un análisis novedoso de la cuestión, escribe asi: «El racionalismo realista de Averroes, con su carácter aperturista y volcado hacia el futuro, no tiene nada que ver con la metafísica emanatista de Alfarabi y Avicena. Es, por el contrario, la coronación de la revolución cultural espoleada por el movimiento renovador de Ibn Túmert $\gg 55$.

51 Risâla, edición de E. Garcia Gómez, pp. 50-52

52 Kitâb al-Mu'yib, cit., pp. 195-196.

5.3 M. Cruz Hernandez, Filosofia Hispano-Musulmana, Madrid, Asociación Española para el Progreso de las Ciencias, 1957, tomo II, p. 31.

54 R. BRUNSCHVIG, "Averroès juriste", en AA.VV., Etudes d'orientalisme dédiées à la mémore de LéviProvençal, Paris, Maisonneuve et Larose, 1962, tomo I, pp. 35-68; W. Montgomery WATt, art. cit, pp. 101-107; D. URvoy, “La pensée almohade dans l'oeuvre d'Averroès", en AA. VV., Multipie Averroès, París, Les Belles Lettres, 1978, pp. 45-53, y Averroès. Les ambitions d'un intellectuel musulman, París, Flammarion, 1998, hay traducción castellana en Alianza Editorial.

${ }_{55}$ El legado filosófico árabe, traducción de M. C. FERIA GarCia, Madrid, Editorial Trotta, 2001, p. 322. 
Otro intelectual árabe, 'Abd al-Hâdî al-Tâzî, nos ofrece el siguiente juicio global sobre el tema: "La opinión de los almohades era, en general, dar libertad de pensamiento, lo que originó el florecimiento de la filosofía, apareciendo grandes pensadores en todas partes. Alentaron la exposición de la crítica y se preocuparon de que los pensadores y científicos fueran muy respetados, bien recibidos y honrados en todas las ocasiones y fiestas oficiales" ${ }^{56}$. Por mi parte, dejo para otra ocasión el estudio detallado de la relación de Averroes con la reforma almohade.

${ }_{56}$ Cit., en Muhammad 'Abd al-Hamid 'Isâ, Historia de la enseñanza en España musulmana (Tesis doctoral inédita, leida en la Universidad Autónoma de Madrid), p. 168. 